\title{
Diabetic Nephropathy in the Arab Gulf Countries
}

\author{
Youssef M.K. Farag a Jamal S. Al Wakeel ${ }^{\mathrm{b}}$

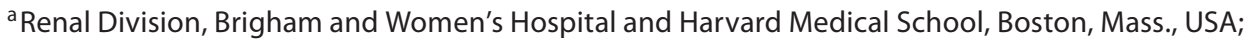 \\ ${ }^{b}$ Renal Division, King Saud University, Riyadh, Kingdom of Saudi Arabia
}

\section{Key Words}

Chronic kidney disease $\cdot$ Diabetes $\cdot$ Diabetic nephropathy . Microalbuminuria $\cdot$ Epidemiology $\cdot$ Risk factors $\cdot$ Arab Gulf countries

\begin{abstract}
While the prevalence of diabetes mellitus is increasing worldwide, one third of the diabetic patients will eventually develop chronic kidney disease. The aim of this review is to present the available data on diabetic nephropathy and its complications in the Arab Gulf countries. This will eventually help to raise the awareness of both government and healthcare systems towards the substantial value of prevention, early detection as well as proper management of both diabetes mellitus and chronic kidney disease. This could be achieved by funding large-scale longitudinal studies, improving training programs (both research and clinical) and increasing the role of media in fighting this epidemic.
\end{abstract}

Copyright $\odot 2011$ S. Karger AG, Basel

In 2007, the estimated worldwide prevalence of all forms of diabetes mellitus (DM) was 246 million people [1] and is expected to double by 2030 [2] while $80 \%$ of DM deaths occur in low- and middle-income countries. Although the prevalence of type $2 \mathrm{DM}$ is generally higher in developed countries, it is increasing most rapidly in developing countries $[1,3,4]$. It has been predicted that the greatest relative increases in diabetes in the next 25 years will occur in the Middle Eastern Crescent, Sub-Saharan Africa and India [4]. Diabetic nephropathy occurs in both type 1 and type $2 \mathrm{DM}$, including diabetes due to genetic defects of $\beta$-cell function. Pathologic abnormalities are noted in patients with long-standing DM before the onset of microalbuminuria. The three major kidney histologic changes in the glomeruli in diabetic nephropathy are mesangial expansion, glomerular basement membrane thickening, and glomerular sclerosis [5, 6]. In 2010, a new pathologic classification of diabetic nephropathy was published in the Journal of the American Society of Nephrology. This classification is proposed as follows. Class I = Glomerular basement membrane thickening: isolated glomerular basement membrane thickening and only mild, nonspecific changes by light microscopy that do not meet the criteria of classes II-IV. Class II = Mesangial expansion, mild (IIa) or severe (IIb): glomeruli classified as mild or severe mesangial expansion but without nodular sclerosis (Kimmelstiel-Wilson lesions) or global glomerulosclerosis in more than $50 \%$ of glomeruli. Class III = Nodular sclerosis (Kimmelstiel-Wilson lesions): at least one glomerulus with nodular increase in mesangial matrix (Kimmelstiel-Wilson) without changes

\section{KARGER \\ Fax +4161306 1234 E-Mail karger@karger.ch} www.karger.com

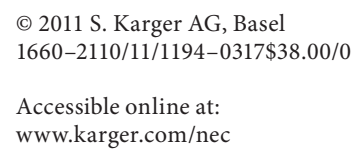




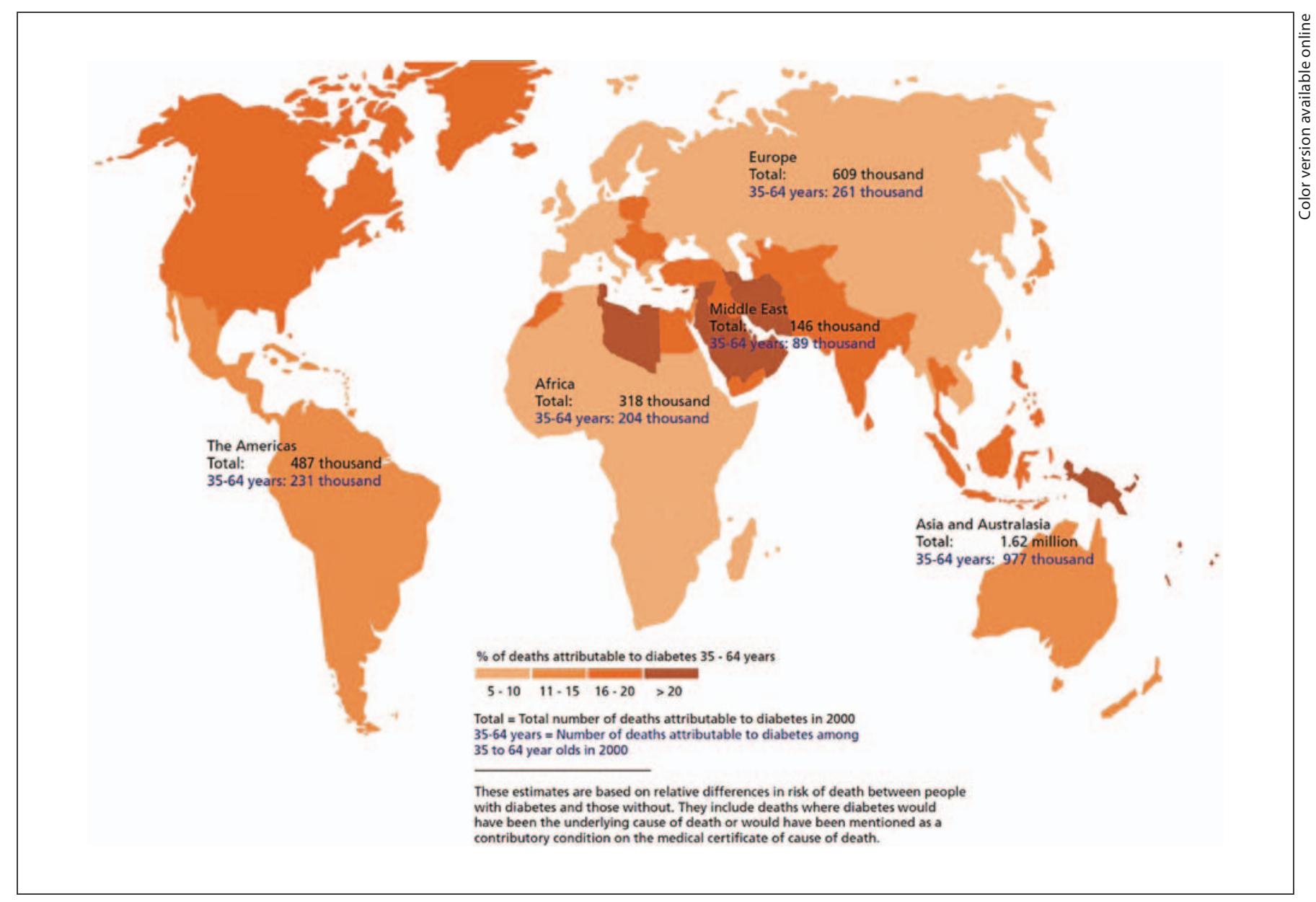

Fig. 1. Deaths attributable to diabetes (with permission from WHO [53; permission No. 40248]).

described in class IV. Class IV = Advanced diabetic glomerulosclerosis: more than 50\% global glomerulosclerosis with other clinical or pathologic evidence that sclerosis is attributable to diabetic nephropathy [54]. However, arteriolar hyalinosis, one of the earliest vascular changes noted in diabetes, was not appreciated in patients with metabolic syndrome [7]. The purpose of this article is to point out the current data on the diabetic nephropathy and its complications in the Arab Gulf countries and raising awareness towards early prevention and treatment of diabetes and chronic kidney disease (CKD).

The Arab Gulf countries are those which have a shore on the Arab Gulf occupying an area of 2.5 million $\mathrm{km}^{2}$ and a total population of 41.15 million people. The region includes Bahrain, Saudi Arabia, Oman, Kuwait, Qatar, and the United Arab Emirates (UAE).

Available evidence on the epidemiology of diabetes in the Arab Gulf is limited. In 2007, four out of the top five countries with diabetes were high-income countries from the Arab Gulf countries $[1,8]$. Data showed that the five countries with the highest diabetes prevalence in the adult population are Nauru (30.7\%), the UAE (19.5\%), Saudi Arabia (16.7\%), Bahrain (15.2\%) and Kuwait (14.4\%) [1]. Figure 1 demonstrates deaths attributable to diabetes and also emphasizes the disproportionate effect of diabetes on mortality in the Arab world compared to elsewhere. Most individuals with diabetes in low- and middle-income countries are middle-aged (45-64 years) and elderly ( $>65$ years) [10].

Most of diabetic patients in Saudi Arabia (90\%) suffer from type $2 \mathrm{DM}$. The prevalence of DM was higher in urban areas (males 12\%, females 14\%) than rural areas (males 7\%, females 7.7\%) [11]. The highest prevalence (49\%) was in urban females aged 51-60 years. In that study, more than half of those diagnosed with diabetes was not aware that they had DM. In the UAE, 23.3\% of 
patients with end-stage renal disease (ESRD) had diabetes as the cause $[12,13]$. Therefore, collectively, since more than a third of individuals with diabetes develop kidney disease [14], it is likely that diabetic kidney disease is also a significant burden in the Arab Gulf countries. We believe that the most important factors increasing the prevalence of diabetes are low physical activity and therefore overweight and obesity, the spread of Western fast food intake (high in fructose - a potential underlying etiology of metabolic syndrome and type $2 \mathrm{DM}$ [15]) and family history and marriage among relatives, which is more common in the Arab Gulf countries. Several studies show the widespread prevalence of obesity-promoting factors like high consumption of fast food, excessive television viewing and not enough exercise [16]. In a study from Saudi Arabia, more than two thirds of the study sample (all Saudi males, $\mathrm{n}=1,139$, mean (SD) age 11.91 [1]) consumes fast foods 3-6 times per week [17]. In Dubai, half of the adolescents of the study sample, which included $49 \%$ males, consumed fast food more than 4 times per week (age range 12-17 years) [18]. Even Arab Americans, referring to Arabs who live in the USA, had extremely high combined rates of glucose intolerance (diabetes, impaired glucose tolerance, and impaired fasting glycemia) which were $32.3 \%$ for women and $49.8 \%$ for men [19]. This may suggest a genetic and/or ethnic component.

\section{Information on Chronic Kidney Disease}

Data on the burden of CKD in the Arab world remains poorly understood. Data available on the exact prevalence and incidence of CKD is limited to patients with ESRD. In the annual report of The Saudi Center for Organ Transplantation (SCOT) [20], the incidence of dialysis in the Kingdom of Saudi Arabia was 136 new cases per million population. As a part of the Global SEEK Project, Screening and Early Evaluation of Kidney Disease, a pilot SEEK-Saudi study was conducted [21]. It aimed at evaluating the burden of CKD and its predictors in the Kingdom of Saudi Arabia using standardized glomerular filtration rate (GFR) prediction equations. It used methodology that has been employed in SEEK-India and SEEK-Thailand [22]. CKD was defined as estimated GFR (eGFR) values $<60 \mathrm{ml} / \mathrm{min}$ per $1.73 \mathrm{~m}^{2}$ or those having albuminuria $\geq 1+$ by urine dipstick. The overall prevalence of CKD among the 491 participants of the SEEKSaudi was found to be $5.7 \%$. CKD in this cohort was largely explained by the presence of albuminuria rather than reduced GFR.

Diabetic Nephropathy in the Arab Gulf Countries

\section{Diabetic Nephropathy}

Diabetic nephropathy is characterized by proteinuria and it is extensively recognized as the leading cause of ESRD. It is also considered the earliest evidence of the kidney damage in diabetic patients. Almost a decade ago, ESRD in patients with type $2 \mathrm{DM}$ was recognized as a 'medical catastrophe of worldwide dimension' [23].

The earliest sign of diabetic nephropathy is considered to be microalbuminuria. Microalbuminuria is defined for a 24-hour urine collection as $30-300 \mathrm{mg}$ of albumin. In a single urine specimen, a level of more than $30 \mathrm{mg}$ of albumin/g of creatinine is considered positive [24]. However, patients with microalbuminuria are referred to as having incipient nephropathy. In patients with type 2 $\mathrm{DM}$, a large percentage of patients are found to have microalbuminuria and overt nephropathy shortly after being diagnosed with diabetes. Scientists attribute this to the presence of diabetes many years before it is actually diagnosed. As diabetic nephropathy progresses, damage to glomeruli causes changes in the microcirculation that result in hyperfiltration occurring in the remaining glomeruli with increased intraglomerular pressure and increased sensitivity to angiotensin II; the single-nephron hyperfiltration with intraglomerular hypertension is itself damaging. This is also supported by the benefit of protein-restricted diet to help in reducing the hyperfiltration. When the eGFR decreases, $20-40 \%$ of type $2 \mathrm{DM}$ patients with microalbuminuria progress to overt nephropathy. Twenty years after the onset of overt nephropathy, only about $20 \%$ will have progressed to ESRD [24].

There are scant data on the epidemiology of diabetic nephropathy in the Arab Gulf population. However, the SCOT states that $12.1 \%$ of the patients on dialysis are suffering from DM and an additional 30.5\% are suffering from both DM and hypertension. In the first cross-sectional analysis assessing the prevalence of microalbuminuria among diabetic patients in the UAE, the overall prevalence rate of microalbuminuria was $61 \% ; 12.5 \%$ had proteinuria among the study sample which was higher among males [25]. This rate was clearly higher than the equivalent rates reported in the Arabian Gulf countries. In 1994, $12.8 \%$ of Saudi diabetic patients had proteinuria (detected by urine dipstick) and $41.3 \%$ had microalbuminuria [26]. Ten years later, a study in Abha City, Saudi Arabia, showed that more than half of the diabetic patients had proteinuria (proteinuria was considered whenever the last and any of the preceding three urine analyses revealed it by the dipstick test provided that the patient was not suffering on the day of the test from fever, urinary

Nephron Clin Pract 2011;119:c317-c323 
tract infections, other renal diseases or congestive heart failure) [27]. Microalbuminuria was found to be $27 \%$ in outpatient type $2 \mathrm{DM}$ in Oman [28]. We did not find any available studies on diabetic nephropathy in adults in Bahrain. A study on patients with type 1 DM of more than 5 years, who were followed by pediatricians in Bahrain, were screened for diabetic nephropathy which was diagnosed in $31 \%$ of the study sample [29].

\section{Risk Factors and Complications of Diabetic Nephropathy}

Diabetic nephropathy in the Arab Gulf countries was positively related to male gender, body mass index, poor diabetes control and presence of diabetic retinopathy and/or neuropathy [25-29]. Other risk factors include genetic susceptibility which may be an important determining factor of both the incidence and severity of diabetic nephropathy $[6,30,31]$ and it is markedly increased in patients with a diabetic sibling or parent who has diabetic nephropathy [32-34]. This factor should be looked into in detail since marriage among relatives is common in these countries. Older age, hypertension and obesity were found to be associated with the development of diabetic nephropathy in other populations [35-39]. A healthier diet and weight loss may reduce proteinuria and improve kidney function among patients with diabetes $[40,41]$. These factors could also have an eminent effect in the Arab Gulf population for the high prevalence of both hypertension and obesity [13, 42-47]. In a retrospective study in Saudi Arabia, diabetic nephropathy was the second most common complication of type 2 DM accounting for $32.1 \%(n=626)$ [48] and there was no significant difference between males and females. However, it appeared significantly earlier among males than females $(12.2 \pm 6.8$ vs. $14.0 \pm 6.8$ years, respectively, $\mathrm{p}=0.005)$. In this study, they retrospectively analyzed the clinical information of 1,952 patients from the computer database of the Security Forces Hospital in Riyadh between 1989 and 2004. In those patients with diabetic nephropathy, the most common complication was hypertension in $96.7 \%$ followed by neuropathy in $67.3 \%$. In a subgroup analysis of the 626 patients with diabetic nephropathy, the mean age at the onset of type $2 \mathrm{DM}$ was $51.6 \pm 12.3$ years. There were 25 patients $(4.0 \%)$ who had diabetes at $<30$ years of age. However, the mean age at the onset of diabetic nephropathy was $61.6 \pm 12.4$ years. Male patients were significantly more susceptible to diabetic complications such as background diabetic reti- nopathy (BDR), peripheral diabetic neuropathy (PDR), foot infection, persistent proteinuria, and progression to ESRD requiring dialysis. However, there was only trend for more prevalence in males than females for other complications such as cataract, proliferative retinopathy, blindness, cardiac complications (including non-specific arrhythmia, atrial fibrillation, acute coronary syndrome and myocardial infarct), stroke, amputation, and death. 148 patients $(23.6 \%)$ had diabetic nephropathy with one associated complication, while the rest had more than one complication $[48,49]$. In order to evaluate the pattern, changes and progression in GFR over time among 621 diabetic nephropathy patients [50], we found that GFR deteriorated from a mean baseline GFR of $78.3 \pm$ 30.3 to $45.1 \pm 24.1 \mathrm{ml} / \mathrm{min} / 1.73 \mathrm{~m}^{2}$ at last visit, with a mean rate of decline in GFR of $3.3 \mathrm{ml} / \mathrm{min} /$ year. Progression of nephropathy was observed in 455 (73.3\%) patients and $250(40.3 \%)$ had doubled their first hospital visit serum creatinine level. At the end of the study, 75 (16.5\%) patients reached ESRD and were eventually dialyzed [50]. Unfortunately, there are no longitudinal cohort studies in the Arab Gulf countries to estimate the mortality from cardiovascular diseases, among others, in diabetic nephropathy patients.

It is clear that diabetic nephropathy is a substantial health problem in the Arab Gulf. It also comprises a significant financial burden. The costs associated with management of diabetic nephropathy are significant [51] and the costs of managing macrovascular complications comprise the largest component, accounting for $85 \%$ of the cumulative costs over the first 5 years and $77 \%$ over the first decade [52]. However, a cost analysis has not been undertaken before in the Arab Gulf. Stopping the progression to ESRD in diabetic nephropathy is crucial to save on the cost of dialysis and transplantation. It will also allow more productivity time for those patients. Going beyond that, early detection and treatment of CKD and DM plus reasonable glycemic control (glycated hemoglobin level of 7.0-7.9\%), weight management and healthy dietary habits will definitely help in reducing the cost, thus alleviating the health and financial burden on the society.

This scarce epidemiological evidence urges the governments and investigators in the Arab Gulf to pursue large-scale longitudinal studies in order to determine the epidemiology, risk factors and complications of DM, $\mathrm{CKD}$ and diabetic kidney disease. In the mean time, proposals to develop registries for non-communicable diseases in this region (diabetes, hypertension, CKD and dyslipidemia, among others) must be adopted by the gov- 
ernments in Gulf countries. Large-scale longitudinal research will help in shedding the light on the tremendous magnitude of these diseases and subsequently adding more funds to develop registries. This will help the governments to better target their resources towards fighting this rising epidemic. It will also guide the academic medical centers in this region to highlight these topics in undergraduate, graduate and postgraduate medical education. In the mean time, expansion in the nephrology services, including clinical and research training programs for nephrologists and allied health professionals, will increase the quality of care provided to those patients.

\section{References}

1 International Diabetes Federation (IDF): Diabetes Atlas: http://www.diabetesatlas.org/ (accessed March 3, 2010).

2 World Health Organization (WHO): Diabetes Facts and Figures: http://www.who.int/ diabetes/facts/en/ (accessed March 3, 2010).

-3 Ramachandran A, Mary S, Yamuna A, Murugesan N, Snehalatha C: High prevalence of diabetes and cardiovascular risk factors associated with urbanization in India. Diabetes Care 2008;31:893-898.

4 Wild S, Roglic G, Green A, Sicree R, King H: Global prevalence of diabetes: estimates for the year 2000 and projections for 2030. Diabetes Care 2004;27:1047-1053.

5 Fioretto P, Steffes MW, Brown DM, Mauer SM: An overview of renal pathology in insulin-dependent diabetes mellitus in relationship to altered glomerular hemodynamics. Am J Kidney Dis 1992;20:549-558.

6 Adler S: Diabetic nephropathy: linking histology, cell biology, and genetics. Kidney Int 2004;66:2095-2106.

7 Alexander MP, Patel TV, Farag YM, Florez A, Rennke HG, Singh AK: Kidney pathological changes in metabolic syndrome: a cross-sectional study. Am J Kidney Dis 2009;53:751759.

8 World Bank Country Classification: http:// data.worldbank.org/about/country-classifications/country-and-lending-groups (accessed March 12, 2010).

$\checkmark$ Khattab MS, Swidan AM, Farghaly MN, Swidan HM, Ashtar MS, Darwish EA, AlMazrooei AK, Mohammad AA: Quality improvement programme for diabetes care in family practice settings in Dubai. East Mediterr Health J 2007;13:492-504.

10 World Health Organization (WHO): Diabetes Programme: http://www.who.int/diabetes/en/ (accessed March 3, 2010).

11 Al-Nuaim AR: Prevalence of glucose intolerance in urban and rural communities in Saudi Arabia. Diabet Med 1997;14:595-602.

12 Albach NM: Increased prevalence rate of diabetes mellitus and associated risk factors in the Arab world. 18th International Diabetes Federation Congress, August 24-29, 2003, Paris P1364.
13 Baynouna LM, Revel AD, Nagelkerke NJ, Jaber TM, Omar AO, Ahmed NM, Naziruldeen MK, Al-Sayed MF, Nour FA: High prevalence of the cardiovascular risk factors in Al-Ain, United Arab Emirates. An emerging health care priority. Saudi Med J 2008;29: 1173-1178.

14 US Renal Data System, USRDS 2007 Annual Data Report: Atlas of Chronic Kidney Disease and End-Stage Renal Disease in the United States. Bethesda, National Institutes of Health, National Institute of Diabetes and Digestive and Kidney Diseases, 2007.

15 Johnson RJ, Perez-Pozo SE, Sautin YY, Manitius J, Sanchez-Lozada LG, Feig DI, Shafiu M, Segal M, Glassock RJ, Shimada M, Roncal C, Nakagawa T: Hypothesis: could excessive fructose intake and uric acid cause type 2 diabetes? Endocr Rev 2009;30:96-116.

16 Alam AA: Obesity among female school children in North West Riyadh in relation to affluent lifestyle. Saudi Med J 2008;29:1139_ 1144.

17 Farghaly NF, Ghazali BM, Al-Wabel HM, Sadek AA, Abbag FI: Life style and nutrition and their impact on health of Saudi school students in Abha, Southwestern region of Saudi Arabia. Saudi Med J 2007;28:415-421.

18 Bin Zaal AA, Musaiger AO, D’Souza R: Dietary habits associated with obesity among adolescents in Dubai, United Arab Emirates. Nutr Hosp 2009;24:437-444.

19 Jaber LA, Brown MB, Hammad A, Nowak SN, Zhu Q, Ghafoor A, Herman WH: Epidemiology of diabetes among Arab Americans. Diabetes Care 2003;26:308-313.

20 Saudi Center for Organ Transplantation (SCOT): 2009 Annual Report: http://www. scot.org.sa/annual-report.html (accessed December 3, 2010).

21 Alsuwaida AO, Farag YM, Al-Sayyari AA, Mousa D, Alhejaili F, Alharbi A, Housawi A, Mittal BV, Singh AK: Epidemiology of chronic kidney disease in the Kingdom of
Saudi Arabia (SEEK-Saudi investigators) - a pilot study. Saudi J Kidney Dis Transpl 2010; 21:1066-1072.
22 Ingsathit $\mathrm{A}$, Thakkinstian $\mathrm{A}$, Chaiprasert $\mathrm{A}$, Sangthawan P, Gojaseni P, Kiattisunthorn K, Ongaiyooth L, Vanavanan S, Sirivongs D, Thirakhupt P, Mittal B, Singh AK, ThaiSEEK Group: Prevalence and risk factors of chronic kidney disease in the Thai adult population: Thai-SEEK Study. Nephrol Dial Transplant 2010;25:1567-1575.

23 Ritz E, Rychlík I, Locatelli F, Halimi S: Endstage renal failure in type 2 diabetes: a medical catastrophe of worldwide dimensions. Am J Kidney Dis 1999;34:795-808.

24 American Diabetes Association: Nephropathy in diabetes (position statement). Diabetes Care 2004;27(suppl 1):S79-S83.

25 Al-Maskari F, El-Sadig M, Obineche E: Prevalence and determinants of microalbuminuria among diabetic patients in the United Arab Emirates. BMC Nephrol 2008;9:1.

26 Alzaid AA, Sobki S, De Silva V: Prevalence of microalbuminuria in Saudi Arabian with non-insulin-dependent diabetes: a clinicbased study. Diabetes Res Clin Pract 1994; 26:115-120.

27 Al-Homrany MA, Abdelmoneim I: Significance of proteinuria in type 2 diabetic patients treated at a primary health care center in Abha City, Saudi Arabia. West Afr J Med 2004;23:211-214.

28 Al-Futaisi A, Al-Zakwani I, Almahrezi A, Al-Hajri R, Al-Hashmi L, Al-Muniri A, Farooqui $\mathrm{M}$ : Prevalence and predictors of $\mathrm{mi}-$ croalbuminuria in patients with type 2 diabetes mellitus: a cross-sectional observational study in Oman. Diabetes Res Clin Pract 2006;72:212-215

29 Al-Hermi BE, Al-Abbasi AM, Rajab MH, AlJenaidi FA, Al-Ekri ZE: Diabetic nephropathy in children with type 1 diabetes mellitus in Bahrain. Saudi Med J 2005;26:294-297.

30 Cooper ME: Pathogenesis, prevention, and treatment of diabetic nephropathy. Lancet 1998;352:213-219.

31 Krolewski AS: Genetics of diabetic nephropathy: evidence for major and minor gene effects. Kidney Int 1999;55:1582-1596.

- 32 Trevisan R, Viberti G: Genetic factors in the development of diabetic nephropathy. J Lab Clin Med 1995;126:342-349. 
-33 Pettitt DJ, Saad MF, Bennett PH, Nelson RG, Knowler WC: Familial predisposition to renal disease in two generations of Pima Indians with type 2 (non-insulin-dependent) diabetes mellitus. Diabetologia 1990;33:438443.

-34 Satko SG, Langefeld CD, Daeihagh P, Bowden DW, Rich SS, Freedman BI: Nephropathy in siblings of African-Americans with overt type 2 diabetic nephropathy. Am J Kidney Dis 2002;40:489-494.

- 35 Tapp RJ, Shaw JE, Zimmet PZ, Balkau B, Chadban SJ, Tonkin AM, Welborn TA, Atkins RC: Albuminuria is evident in the early stages of diabetes onset: results from the Australian Diabetes, Obesity, and Lifestyle Study (AusDiab). Am J Kidney Dis 2004;44: 792-798.

\36 Mogensen CE, Hansen KW, Pedersen MM, Christensen CK: Renal factors influencing blood pressure threshold and choice of treatment for hypertension in IDDM. Diabetes Care 1991;14(suppl 4):13-26.

\37 Gelber RP, Kurth T, Kausz AT, Manson JE, Buring JE, Levey AS, Gaziano JM: Association between body mass index and CKD in apparently healthy men. Am J Kidney Dis 2005;46:871-880

>38 Ejerblad E, Fored CM, Lindblad P, Fryzek J, McLaughlin JK, Nyrén O: Obesity and risk for chronic renal failure. J Am Soc Nephrol 2006; 17:1695-1702.

-39 De Boer IH, Sibley SD, Kestenbaum B, Sampson JN, Young B, Cleary PA, Steffes MW, Weiss NS, Brunzell JD: Diabetes Control and Complications Trial/Epidemiology of Diabetes Interventions and Complications Study Research Group. Central obesity, incident microalbuminuria, and change in creatinine clearance in the epidemiology of diabetes interventions and complications study. J Am Soc Nephrol 2007; 18:235-243.
40 Morales E, Valero MA, León M, Hernández E, Praga M: Beneficial effects of weight loss in overweight patients with chronic proteinuric nephropathies. Am J Kidney Dis 2003; 41:319-327.

-41 Saiki A, Nagayama D, Ohhira M, Endoh K, Ohtsuka M, Koide N, Oyama T, Miyashita Y, Shirai K: Effect of weight loss using formula diet on renal function in obese patients with diabetic nephropathy. Int J Obes (Lond) 2005;29:1115-1120.

42 Nazim Uddin K: Prevalence of hypertension in Saudi Arabia. Practitioner East Mediterr Ed 1994;805-806.

43 Al-Nozha MM, Ali MS, Osman AK: Arterial hypertension in Saudi Arabia. Ann Saudi Med 1997;17:170-174.

44 Al-Nozha MM, Abdullah M, Arafah MR, Khalil MZ, Khan NB, Al-Mazrou YY, et al: Hypertension in Saudi Arabia. Saudi Med J 2007;28:77-84.

45 El-Shahat YI, Bakir SZ, Farjou N, Hashim T, Bohaliga A, Al-Hossani H, et al: Hypertension in UAE citizens - preliminary results of a prospective study. Saudi J Kidney Dis Transpl 1999;10:376-381.

46 Abdulle AM, Nagelkerke NJ, Abouchacra S, Pathan JY, Adem A, Obineche EN: Undertreatment and underdiagnosis of hypertension: a serious problem in the United Arab Emirates. BMC Cardiovasc Disord 2006;6: 24.

47 Maziak W, Rastam S, Mzayek F, Ward KD, Eissenberg T, Keil U: Cardiovascular health among adults in Syria: a model from developing countries. Ann Epidemiol 2007;17: 713-720.
48 Al-Wakeel JS, Sulimani R, Al-Asaad H, AlHarbi A, Tarif N, Al-Suwaida A, Al-Mohaya S, Isnani AC, Alam A, Hammad D: Diabetes complications in 1,952 type 2 diabetes mellitus patients managed in a single institution in Saudi Arabia. Ann Saudi Med 2008;28: 260-266.

-49 Al Wakeel JS, Alsuwaida A, Isnani AC, Alharbi A, Alam A: Concomitant macro- and microvascular complications in diabetic nephropathy. Saudi J Kidney Dis Transpl 2009; 20:402-409.

$50 \mathrm{Al}$ Wakeel JS, Isnani AC, Alsuwaida A, Alharbi A, Shaffi SA, Al Mohaya S, Al Ghonaim M: Factors affecting the progression of diabetic nephropathy and its complications: a single-center experience in Saudi Arabia. Ann Saudi Med 2011;31:236-242.

51 Atthobari J, Asselbergs FW, Boersma C, de Vries R, Hillege HL, van Gilst WH, Gansevoort RT, de Jong PE, de Jong-van den Berg LT, Postma MJ: PREVEND IT Study Group: Cost-effectiveness of screening for albuminuria with subsequent fosinopril treatment to prevent cardiovascular events: A pharmacoeconomic analysis linked to the prevention of renal and vascular end-stage disease (PREVEND) study and the prevention of renal and vascular end-stage disease intervention trial (PREVEND IT). Clin Ther 2006; 28:432-444.

52 Caro JJ, Ward AJ, O’Brien JA: Lifetime costs of complications resulting from type 2 diabetes in the United States. Diabetes Care 2002;25:476-481

53 Diabetes Action Now. An Initiative of the World Health Organization and International Diabetes Federation, 2004, WHO Permission No. 40248.

54 Tervaert TW, Mooyaart AL, Amann K, et al: Pathologic classification of diabetic nephropathy. J Am Soc Nephrol 2010;21:556563.

\title{
Editorial Comment
}

\author{
M. El Nahas, Sheffield
}

The review by Farag and Al Wakeel reminds readers of the major crisis facing some emerging countries including those of the Arab Gulf in relation to the global epidemic of type 2 diabetes mellitus. Data show that of the five countries with the highest diabetes prevalence in the adult population, four are within the Arab Gulf region - the United Arab Emirates (19.5\%), Saudi Arabia (16.7\%), Bahrain (15.2\%) and Kuwait (14.4\%). This is likely to be the direct consequence of the parallel epidemic of obesity, hence the terminology of diabesity. Of concern is the rising prevalence of obesity in many of these countries in children and adolescents. Such a crisis has to be put in the broader context of the global crisis related to the rise of non-communicable diseases (NCDs). These in turn impact on the rising cardiovascular mortality in emerging economies. Two of three deaths every year are attributable to NCDs. Four fifths of these deaths are in low- and middle-income countries and a third occurring in people younger than 60 years of age. The rising burden of obesity, diabetes and NCDs in general are caused by 
the ageing of the population but also the risks associated with globalization and urbanization [1]. The forthcoming UN high-level meeting (September 2011) on NCDs will be an opportunity to address and generate a sustained global movement against NCDs and the associated disabilities and premature deaths. Changes in lifestyle, promotion of healthy eating and physical activity, salt reduction, accelerated tobacco control and reduction of harmful alcohol consumption are all target policies that will require leadership as well as international cooperation. This should ultimately aim to reduce NCD-related death rates by $2 \%$ per year [2]. The Arab world has risen against many political systems in 2011, it is high time it also seriously challenges its healthcare systems if they do not address the growing crisis of NCDs!

\section{References}

El Nahas M: Obesity and diabetes in the developing world - a growing challenge. N Engl J Med 2007;356:213-215.

2 Beaglehole R, et al: Priority actions for the non-communicable disease crisis. Lancet 2011;377:1438-1447. 